\title{
Heart rate variability in healthy subjects: effect of age and derivation of normal ranges for tests of antonomic function
}

Sir,

The study on the effect of age on heart rate variability in normal subjects by O'Brien et al (1986;55: 348-54) ${ }^{1}$ deserves comment.

(a) The confidence limits obtained are lower than in previous studies. This is attributed to the larger number and more uniform age distribution of the subjects. Differences in selection criteria and test procedures are, however, another explanation. More information should, therefore, be provided on the subjects and test conditions such as values for resting heart rate, supine blood pressure, the time of the day the experiments were performed, and the intake of coffee and cigarettes before the experiments. ${ }^{1}$

(b) Information is not given on the period of supine rest before the patient stood up. This is an important omission since we have shown that the duration of rest before standing has a profound $(20-40 \%)$ influence on the magnitude of the initial heart rate response induced by standing up. ${ }^{2-4}$

(c) The instant at which the initial peak heart rate increase evoked by standing up was observed by O'Brien et al seems to have occurred earlier than we found in our studies. ${ }^{235}$ This is not surprising since the recording was not started at the onset of standing up, ${ }^{2}$ but at the moment the subject became erect. The latter procedure is not correct from a physiological point of view. ${ }^{3}$

(d) I agree that cardiovascular autonomic function should be assessed by a combination of tests and that the establishment of normal ranges in relation to age is also important. But ultimately an understanding of the physiological mechanisms involved is the most important factor. ${ }^{356}$

Unfortunately, O'Brien et al leave us with much numerical information, but little physiological interpretation.

W Wieling,

Department of Medicine,

Academic Medical Centre,

Meibergdreef 9,

$1105 \mathrm{AZ}$ Amsterdam,

The Netherlands.

\section{References}

1 O'Brien IAD, O'Hare P, Corrall RJM. Heart rate variability in healthy subjects: effect of age and the derivation of normal ranges for tests of autonomic function. Br Heart $\mathcal{F}$ 1986;55:348-54.

2 Wieling W, van Brederode JFM, de Rijk LG, Borst C, Dunning AJ. Reflex control of heart rate in normal subjects in relation to age: a data base for cardiac vagal neuropathy. Diabetologia 1982;22:163-6.

3 Borst C, Wieling W, van Brederode JFM, Hond A, de Rijk LG, Dunning AJ. Mechanisms of initial heart rate response to postural change. Am $\mathcal{f}$ Physiol 1982;243:H676-81.

4 Borst C, van Brederode JFM, Wieling W, van Montfrans GA, Dunning AJ. Mechanisms of initial blood pressure response to postural change. Clin $S c i$ 1984;67:321-7.

5 Wieling W, Borst C, van Lieshout JJ, et al. Assessment of methods to estimate impairment of vagal and sympathetic innervation of the heart in diabetic autonomic neuropathy. Neth F Med 1985;28:383-92.

6 Bennett T. Physiological investigation of diabetic autonomic failure. In: Bannister R, ed. Autonomic failure. $A$ textbook of clinical disorders of the autonomic nervous system. Oxford: Oxford University Press, 1983:337-70.

This letter was shown to the authors, who reply as follows:

Sir,

We are grateful for Dr Wieling's comments but feel that he may have misinterpreted the purpose of our study: this was to provide a practical and reliable basis for the detection of impaired heart rate variability, not a physiological interpretation of our tests. These are used widely in routine clinical practice under uncontrolled conditions. We choose, therefore, to investigate normal subjects under similar circumstances, not under carefully controlled laboratory conditions. Heart rate variability is subject to a host of environmental, psychological, and neurohormonal influences that all contribute to the large coefficients of variation observed with these tests. ${ }^{12}$ 